\title{
¿Nueva, novísima o novedosa? \\ De la novísima poesía según Edgardo Antonio Vigo a la poesía experimental digital
}

\author{
Claudia Kozak• \\ Universidad de Buenos Aires / CONICET
}

\section{Resumen}

A partir de la discusión en torno de la noción de «novísima poesía», tal como la propuso Edgardo Antonio Vigo, el texto analiza vinculaciones entre la poesía experimental en la que se enmarcó la propuesta de Vigo y la poesía digital. Aunque Vigo no haya escrito nunca poesía digital, el tipo de poética que impulsó está implicada en una gran parte de las experimentaciones poéticas digitales. El hilo conductor de la argumentación se ubica del lado de las potencialidades de la poesía experimental digital, en vinculación con un tipo de poética como la de Vigo, para abrir la experiencia artística a nuevas variedades de mundo por fuera de los caminos estandarizados de las sociedades informatizadas en las que se inscribe y en oposición a su mera novedad.

\section{Palabras clave}

- novísima poesía · poesía experimental · poesía digital · Edgardo Antonio Vigo

\begin{abstract}
Focusing on the notion of "novísima poesía» - the newest poetry - developed by Edgardo Antonio Vigo, this article analyses relationships between digital and experimental poetry. Even if Vigo never wrote digital poetry, the kind of poetics promoted by him can be easily intertwine with digital poetry
\end{abstract}

\footnotetext{
- Doctora en Letras (UBA). Investigadora CONICET/Instituto Gino Germani (UBA). Profesora Titular Regular de la Facultad Ciencias Sociales, UBA. Profesora Adjunta Interina, Facultad Filosofía y Letras, UBA. Dirige Ludión. Exploratorio latinoamericano de poéticas/políticas tecnológicas (http://www.ludion.org). Coordina la Red de Literatura Electrónica Latinoamericana (http://litelat.net/). Integra el Board of Directors de la Electronic Literature Organization (https://eliterature.org/). Algunos de sus libros son: Poéticas/ políticas tecnológicas en Argentina -1910-2010-; Tecnopoéticas argentinas. Archivo blando de arte y tecnología; Deslindes. Ensayos sobre la literatura y sus límites en el siglo XX; Contra la pared. Sobre graffitis, pintadas y otras intervenciones urbanas.
} 
experimentation. Argumentation is based on the potentiality of experimental poetry digital, articulated whit the kind of poetics Vigo encouraged, to opening artistic experience towards new forms of life, surpassing standardized paths within informational societies and in opposition to its mere novelty.

\section{Key words \\ - Novísima Poesía · Experimental Poetry · Digital Poetry · Edgardo Antonio Vigo}

Entre marzo y abril de1969, se presentó en el Instituto Di Tella de Buenos Aires la «Expo/Internacional de Novísima Poesía/69», una muestra organizada por Edgardo Antonio Vigo que incluyó una importante selección de poesía experimental de artistas de diversas partes del mundo y que resulta fundamental para comprender el alcance en la década del sesenta de la poesía experimental que enfatiza el trabajo con la materialidad del poema en un sentido no representacional. En esta poesía, la materia dice por sí misma y no como vehículo de contenidos que la trascienden. El catálogo de la muestra reproducía, además de imágenes de «obras» ${ }^{1}$, breves textos teórico-críticos que permiten dimensionar el carácter material de la novísima poesía. Así por ejemplo, en el texto de Vincenzo Accame se lee: «En esta nueva poesía es entonces el quehacer técnico lo que inicialmente prevalece; se trata de experimentar recursos, instrumentos, materiales; de llevar al interior de la poesía esos experimentos; y en consecuencia crear el Código de un nuevo lenguaje» (Expo/Internacional de Novísima Poesía/69, s.p).

De acuerdo con el estudio realizado por Magdalena Pérez Balbi:

La exposición contó con más de 150 obras, pertenecientes a 114 artistas de 15 países y dividida en tres secciones. En la primera se exponían más de 85 libros y libros-objeto y 40 revistas, la mayoría provenientes de la biblioteca personal de Vigo (...) La segunda sección, donde residía el mayor número de obras, la conformaban las obras de Poesía Visual (...) En la última sala, casi en penumbras, se presentaba la sección de poesía sonora, con obras de quince poetas paradigmáticos. (Pérez Balbi, 2010: 85)

Apenas finalizada en Buenos Aires, la muestra pasó con el nombre de «Novísima Poesía/69", y algo reducida, al Museo Provincial de Bellas Artes, en la ciudad de La Plata, donde Vigo vivió toda su vida, con la excepción de su viaje iniciático a Europa en los años cincuenta. No es intención de este artículo presentar un análisis exhaustivo de estas dos muestras, ya analizadas por diversos autores (Davis, 2006; Barisone, 2012; Pérez Balbi, 2006 y 2010), sino tomarla como punto de inflexión o síntoma que permite analizar las relaciones que se dieron en ese momento entre 
dos series de nociones imbricadas: la serie de lo nuevo, novísimo y experimental, por un lado, y la serie de la materialidad, la técnica y la tecnología, por el otro. Ello, con vistas a reflexionar acerca de cómo ese punto de inflexión que tuvo como uno de sus principales protagonistas en nuestro país a Edgardo Antonio Vigo puede resultar significativo para la comprensión de la poesía digital contemporánea ${ }^{2}$.

Las Expos instalaron una asociación entre la poesía experimental —visual, sonora, objetual, performática- y la noción de lo nuevo, o mejor, de lo más nuevo, lo novísimo. A su vez, instalaron una asociación entre lo novísimo y la materialidad técnica/tecnológica. Discutiré más adelante las vinculaciones que suelen establecerse en la sociedad contemporánea entre novedad y tecnología; por el momento baste notar que novísima poesía era una manera de nombrar, desde la perspectiva de Vigo, no tanto un tipo de poesía que llegaba después en el tiempo, y que era así más actual — aunque para él también lo fuera - sino que transformaba una serie de conceptos heredados como obra (orgánica y completa), autor (individual y portador de un «estilo») y lector (contemplativo), lo que redundaba en una nueva experiencia estética provocativa y desautomatizadora.

\section{Novísima Poesía y el arte tecnológicamente realizable}

Aunque al interior de la novísima poesía Vigo intervino muchas veces con poesía visual y objetual, en la que lo nuevo-experimental ${ }^{3}$ se vinculaba con el cuestionamiento de la versificación, de los límites entre distintos lenguajes artísticos - literatura, artes plásticas, por ejemplo-y de la referencialidad de signos y símbolos, una de sus versiones quizá más radicales de la novísima poesía fue lo que dio en llamar "poesía para y/o a realizar», un tipo de poesía altamente conceptual en la que primaba no la obra como unidad completa y atribuible a un autor, sino el proceso de construcción a partir de «instrucciones» para que fueran los participantes del hecho poético quienes elaboraran a su modo los poemas.

La «poesía para y/o a realizar» entabló un diálogo — según Vigo de continuidad y superación - con propuestas previas: el "poema proceso» de artistas posconcretos brasileños como Wlademir Dias Pino, Álvaro de Sá, Neide Dias de Sá ${ }^{4}$ o el «poema para armar» del poeta experimental francés Julien Blaine. Para Vigo, su propuesta se diferenciaba por plantear la creación del poema por parte de un participante activo con escasa predeterminación del artista: el lector/experimentador ya no sería un armador de elementos predeterminados puestos a su disposición por el autor sino un constructor a partir de una idea. Vigo encontraba «una especie de progresión hacia un logro" (1970: 0'9) en el tránsito desde esas otras manifestaciones de la novísima poesía hasta la que él proponía, en particular en relación con el pasaje entre distintas instancias del lectura. En esta progresión, el lector pasaba de una a otra por las instancias de «observador-participante-armador-realizador» o incluso «constructor de poemas a realizar» (Vigo, 1970: 0’9).

De todos modos, si bien su propuesta se diferenciaba entonces de la de otros experimentadores de la novísima poesía, da bastante relevancia a los aspectos de 
aquellas otras propuestas que apoyan su propia idea de una poesía en potencia, a realizar no en la instancia clásica autoral sino en la recepción. Así por ejemplo, cita unas palabras de Neide Dias de Sá en las que considera al artista ante todo como un «programador de proyectos» (Neide Dias de Sá en Vigo 1970: 0’8) ${ }^{6}$. Como explicará Neide Dias de Sá muchos años después en una entrevista para el sitio web Musseu do essencial e do além disso, de la artista visual y poeta experimental Regina Célia Pinto: «O Poema Processo é aquele que, a cada nova experiência, inaugura processos informacionais. Tem como ponto de partida a Matriz geradora de séries» (Dias de Sá, s.f. párrafo 6).

Del mismo modo, sostenía Vigo respecto del poema proceso y del poema para armar:

Existe la construcción de un objeto poético o poema novísimo determinado por un "programador» de proceso o de poema para amar. Acá el término "programador» suple al de «artista». Éste ya está perimido por la acción y relación que mantiene con la sociedad. Si hablamos de un arte seriado, tecnológicamente realizable, con formas de fácil reproducción y anexiones técnicas es obvio seguir utilizando este término. (Vigo, 1970: 0’8) (negritas y comillas en el original, énfasis mío)

Comenta Moacy Cirne (1970: 1'1), respecto de la diferencia entre la poesía concreta anterior y el movimiento del poema/proceso, que se establece en ese pasaje un énfasis menos en la estabilidad y la estructura de una obras producidas y más en los procesos de producción. En esta línea no hay obras sino proyectos e instrucciones, es decir «programas» o «algoritmos». Como por ejemplo, en el «Poema a Realizar» del propio Vigo (1970: 2'7) aquí reproducido que incluía, primero, las instrucciones y, luego, el espacio gráfico para la «realización» del poema (Figura 1):

\section{Poema a Realizar}

\section{Basado en un PLEBSICITO GRATUITO}

Instrucciones: Plantéese el interrogante que usted quiera. Posteriormente escriba con un elemento gráfico libre (tanto en su técnica como color) el «SÍ» o «NO» dentro o fuera de los cuadrados impresos) como contestación al mismo. ELIJA UD. SU CASILLERO.

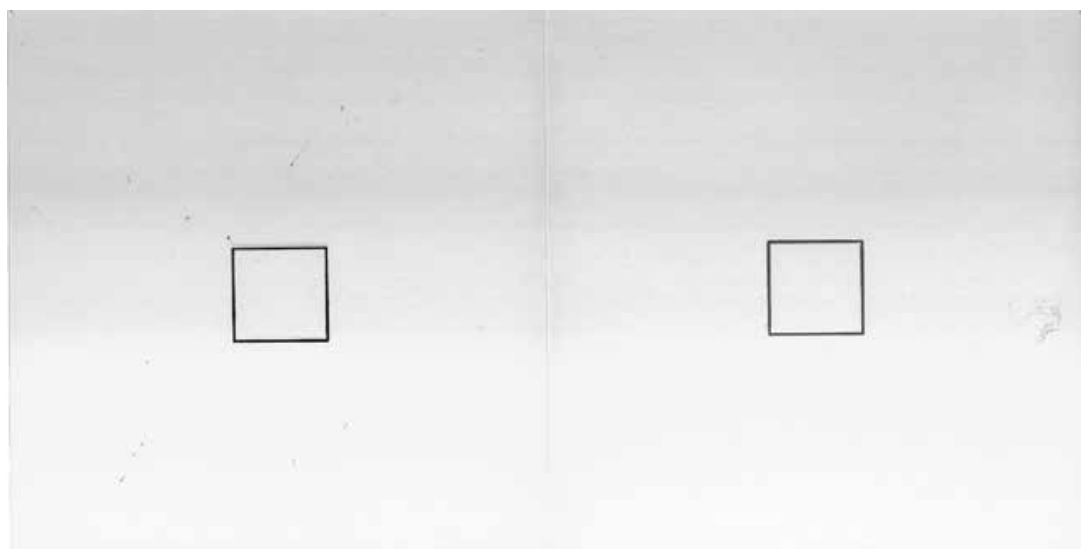

Figura 1. Edgardo Antonio Vigo. Poema a Realizar. Basado en un PLEBSICITO GRATUITO. 
A juzgar por este poema que Vigo incluyó en su libro Poesía para y/o a realizar (1970), el poema mismo como obra o producto se tornaba inexistente, en cuanto se trataba de un programa para producir poesía y no de un poema propiamente dicho, ya que el mismo se diluía en potenciales poemas a realizar por el lector, a los que sólo se podría acceder en experiencias de creación que excedían por completo lo publicado.

En la poesía digital contemporánea existen muchos ejemplos de producciones que sólo son programas que el lector/interactor pone a funcionar a partir de «datos» de su propia imaginación y escritura poética. Para dar sólo un par de casos relevantes en la poesía digital latinoamericana, se pueden citar PAC, Poesía Asistida por Computadora (2006) del mexicano Eugenio Tisselli, o la serie que el argentino Milton Läufer ubica bajo el título de WriterTools ${ }^{\mathrm{TM}}\left(2014-\right.$ pres.) ${ }^{7}$. En el primer caso, se trata de un programa en el que a partir de versos "semilla» ingresados por el lector/realizador se generan sustituciones lexicales remotas que dan origen a nuevos versos (Figura 2) ${ }^{8}$. En el segundo caso, cada «obra a realizar» presenta un recurso diferente - autocorrección, sustitución, figuración, codificación, entre otros- puesto en marcha por el lector/realizador cuando ingresa un tema o texto a elección. El texto ingresado muta así en la «realización» (Figura 3).

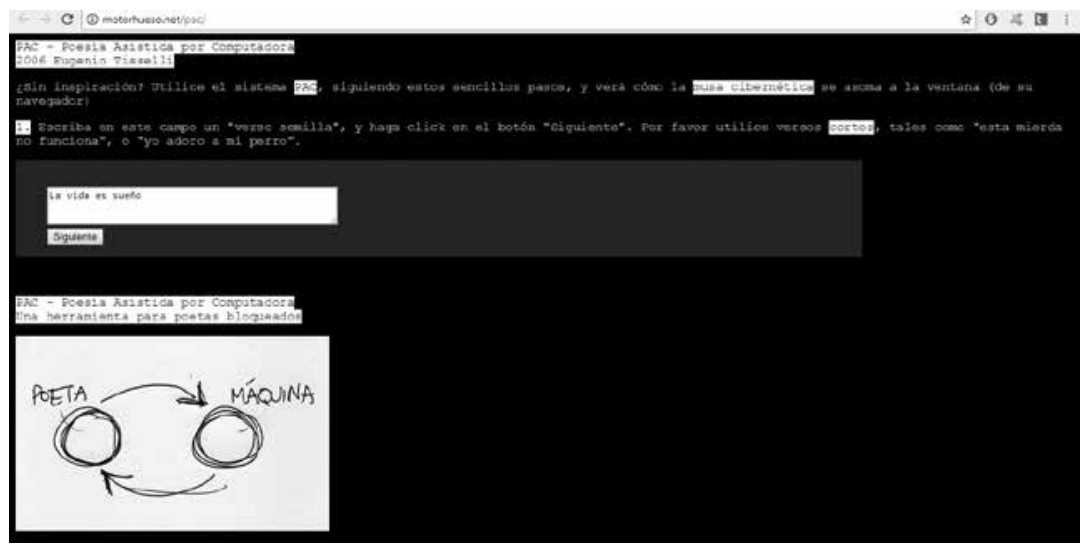

Figura 2. PAC. Poesía Asistida por Computadora, Eugenio Tisselli. Captura de pantalla.

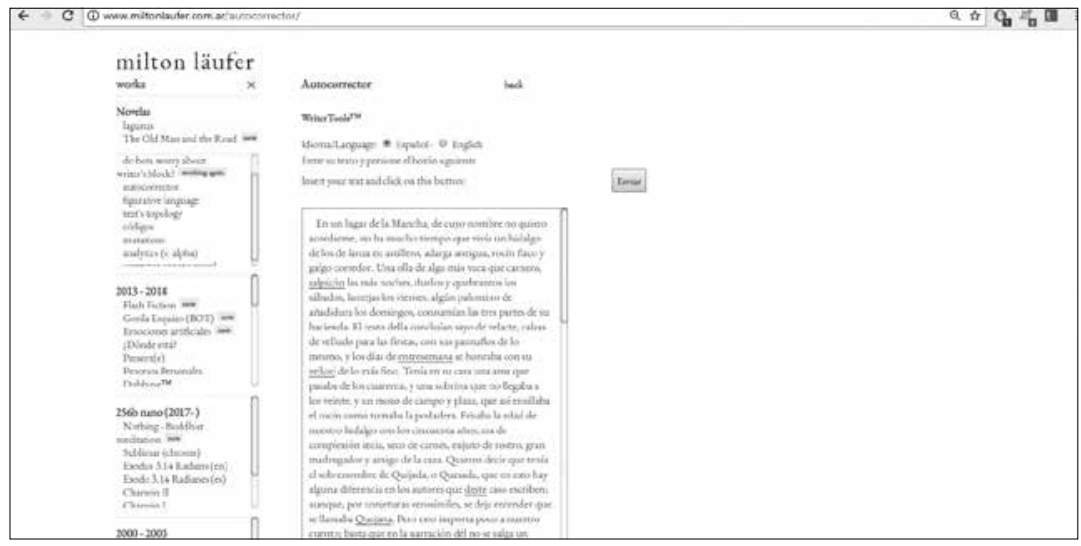

Figura 3. WriterTools. Autocorrector. Milton Läufer. Captura de pantalla. 
Así, este énfasis en el artista programador de procesos informacionales que estaba en la base del poema proceso pero también de la poesía para y/o a realizar resulta fundamental para acercar la propuesta de Vigo a lo que en décadas posteriores se expandirá como poesía digital. No sólo en la concepción de una poesía como programa sino también en la participación del lector/interactor. La relación entre los procesos participativos en la constitución de las prácticas artísticas de los años sesenta del siglo XX y las prácticas interactivas en las artes digitales — de las cuales la literatura digital forma parte — ha sido analizada en muchas ocasiones, destacando a la vez que el arte digital, ciertamente, no inventó la interactividad (Aarseth, 1997; Brea 2002) ${ }^{9}$. El caso de Vigo es un buen ejemplo. Aunque Vigo nunca incursionó en el arte digital por sí mismo, su poética queda implicada en muchos de los desarrollos de esa zona de las artes. Como señala Charly Gradín en su texto «Edgardo Antonio Vigo, o el arte digital desenchufado»:

\footnotetext{
Si volvemos la vista desde nuestro presente hiper-tecnologizado podríamos pensar en Vigo como un militante de las experiencias visuales de la comunicación a distancia, inmersivas e interactivas, que se volverían habituales en los últimos años. No porque Vigo haya intentado implementarlas desde sus obras impresas en papel, muy alejadas de cualquier tecnología electrónica, sino porque desde sus poemas visuales y revistas hasta sus obras hechas de instrucciones a ser realizadas por los espectadores/usuarios, se trataba siempre de sugerir que había una dimensión de diálogo por explorar a través del arte, cuyas posibilidades eran potencialmente infinitas. (Gradín, 2014: 208)
}

De hecho, aun si Vigo por sí mismo no realizó arte digital, unos años antes de las Expos, en el decisivo número 20 de diciembre de 1966 de la revista Diagonal $C e r 0^{10}$, de la que Vigo era impulsor principal y editor, se había publicado una serie de tres poemas de Omar Gancedo, titulados IBM, que constituyen el primer esbozo de poesía digital en nuestro país. La serie incluía tres poemas visuales codificados en tarjetas perforadas IBM de 80 columnas. Las perforaciones de las tarjetas codificaban el texto que también podía leerse en lenguaje natural como línea continua de texto en la sección media de cada tarjeta. La elaboración de cada poema había seguido un proceso de dos pasos: primero, perforación de las tarjetas utilizando la codificación estándar en aquel momento y una perforadora IBM modelo 534, lo que implicaba una suerte de "programación» para que, en un segundo paso, una Card Interpreter —es decir una máquina de computar programada para decodificar el input de las tarjetas - decodificara el texto y lo imprimiera sobre la tarjeta ${ }^{11}$. Adicionalmente, en Diagonal Cero, los poemas aparecían transcriptos en la misma página donde aparecía la imagen de cada tarjeta. Vigo no dudó en nombrar estos experimentos como "poesía electrónica» y a Gancedo, su autor, como "cibernético». Así aparecen en uno de los volantes de promoción de la revista que los integrantes del Movimiento Diagonal Cero arrojaron en 1967 en ocasión de happening realizado por Jean-Jacques Lebel en el Instituto Di Tella (Figura 4$)^{12}$. 


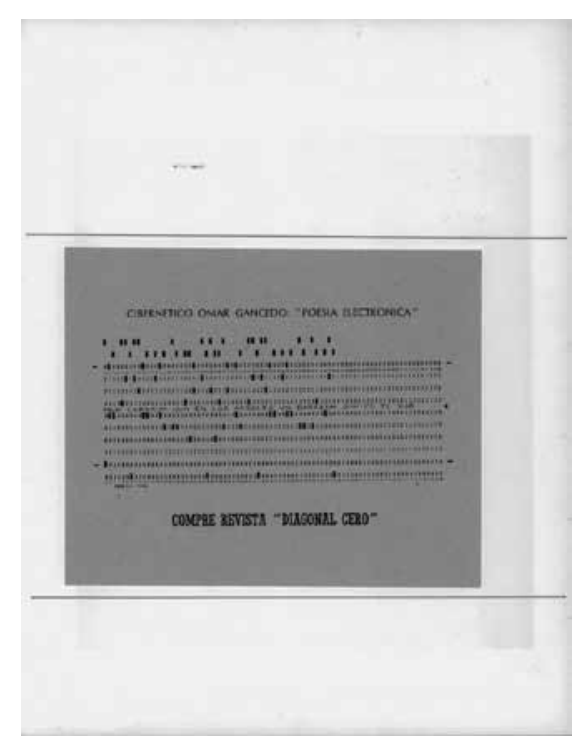

Figura 4. Volante de promoción de Diagonal Cero. Cibernético Omar Gancedo: «Poesía Electrónica»

Si bien estos poemas de Gancedo no anticipan la poesía para y/o a realizar (por el lector) en cuanto se ofrecen como producciones acabadas que a simple vista semejan ser sobre todo piezas de poesía visual, sí permiten dar continuidad en el tiempo, antes y después de las Expos, a la idea del artista/programador que es central para una parte importante de la poesía digital contemporánea. Tal continuidad está sostenida por la idea de una poesía en cuanto «máquina» que produce lenguajes, esto es, programas o máquinas/lenguajes para la producción de piezas que realizarán los lectores.

Asimismo, otro de los aspectos centrales que habla de líneas de continuidad entre la poética de Vigo y la poesía digital se vincula con el amplio desarrollo de lo que en el campo específico se conoce como "poesía animada o cinética" (Funkhouser 2007, Hayles 2008) esto es, un subgénero de poesía digital que reelabora en clave multimedia la poesía experimental visual. La poesía digital animada da lugar a experiencias poéticas en la que los textos, la tipografía, las imágenes adquieren movimiento, se amalgaman con sonidos o, en los casos de producciones interactivas, resultan «realizadas» por los lectores. Esto se vincula muy particularmente con las genealogías que suelen trazarse entre la poesía visual experimental y la poesía digital. Muchos autores (Glazier 2002, Beiguelman 2010, Funkhouser 2007, Hayles 2006 y 2009, Perloff 2006, entre otros) han señalado ya este tipo de asociación. Así, por ejemplo, en su libro Digital Poetics. The Making of E-Poetries (2002), Loss Pequeño Glazier señala no solamente las vinculaciones entre la poesía digital y la poesía concreta de mediados del siglo XX en virtud de la disposición visual no semántica del texto (2004: 36) sino también por la clara internacionalización de ambos tipos de poesía experimental (2004: 152). Esa continuidad se observa también en el discurrir temporal de la práctica de algunos de los poetas que participaron del movimiento de poesía concreta desde los años cincuenta y sesenta. Así, el propio Augusto de Campos ha realizado poemas animados digitalmente en continuidad con su poesía visual-concreta. Por dar un ejemplo significativo, el «Poema-Bomba» (1983-1997), con música de Ciro de 
Campos, permite no sólo hacer estallar la tipografía con movimiento explosivo sino también incorporar la voz retumbante que dice la palabra y complementa la experiencia sensorial de aprehensión del poema. Más aun, la genealogía que puede trazarse desde la poesía digital animada hacia la poesía concreta y, más en general visual experimental, no se detiene hacia atrás a mediados del siglo XX sino que fácilmente puede remontarse hacia inicios del siglo. Muchas veces se repiten inclusive a lo largo de esa genealogía ciertos «patrones de visualidad». Un caso es la forma-espiral, tan cara a la poesía visual, que aparece en muchas obras de poesía digital. Así por ejemplo, para remitir sólo al caso iberoamericano, podemos ver la espiral y experimentar su movimiento en obras como la «Dedicatoria Espiral» en Góngora WordToys (2011) de Belén Gache, poema con programación de Milton Läufer, o en el propio poema "Círculo» (2003) de Läufer. Asimismo, existe continuidad visual entre el «Poema-Bomba» de Augusto de Campos y "Jaqueca» del poeta peruano, residente por mucho tiempo en Argentina, Alberto Hidalgo, cuya obra de los años veinte se inscribe en las vanguardias latinoamericanas ${ }^{13}$. En ambos poemas, en efecto, las letras se dispersan en forma de estallido. De modo similar, puede encontrarse continuidad visual entre algunos poemas del libro Hélices, de poeta ultraísta español Guillermo de Torre — también residente mucho tiempo en Argentina- y el primero de los poemas de la serie Eliotians de Iván Marin ${ }^{14}$. En ambos casos, por ejemplo, los versos se disponen en figuraciones tipo abanico. En cualquiera de esos ejemplos comparados, la diferencia se da por el movimiento que exhiben las obras de poesía digital —más el sonido en «Poema-bomba» y el funcionamiento random en la serie Eliotians — en contraste con los textos inmóviles publicados en papel.

Por otra parte, volviendo a Vigo, no es ocioso señalar que uno de los autores cuya poesía visual fue presentada en la Expo/Internacional de Novísima Poesía/69 era el canadiense bp Nichol quien más adelante, a mediados de la década del ochenta, incursionó notablemente en poesía digital animada con su serie de piezas First Screening programadas en AppleSoft BASIC ${ }^{15}$. Además, en la Expo del Di Tella se expuso el libro que el poeta estadounidense Emmett Williams, vinculado con Fluxus, había publicado en 1967, titulado An Anthology of Concrete Poetry (Williams, 1967). Tampoco en este caso es ocioso mencionar que en $1966 \mathrm{Wi}$ lliams había reelaborado con ayuda de una computadora un experimento poético combinatorio cuyas primeras versiones manuales había realizado en la década del cincuenta. Como explicaba Williams en una carta a su esposa, la artista Ann Noël: "For the title I chose IBM, an understandable tribute to the muse's assistant» (Williams, 1973b: 277) ${ }^{16}$. En su libro A Valentine for Noël (1973a), Williams presentó los textos ajustándolos a distintos juegos tipográficos en la tradición de la poesía visual ${ }^{17}$; lo decisivo, con todo, es que combinaba el énfasis en la poesía visual con una producción de los textos como resultado de permutaciones desencadenadas por una serie de reglas predeterminadas por el autor y utilizando una computadora. Lo que se incluye habitualmente dentro del subgénero de literatura digital llamado "generadores de texto", es decir, programas que combinan mediante algoritmos ciertas unidades mínimas predeterminadas, dando lugar a generación automática de textos proliferantes ${ }^{18}$.

Los poemas IBM, tanto los de Gancedo como los de Williams, realizados en el mismo año ${ }^{19}$, muestran una conexión estrecha y algo paradójica entre lo conceptual y lo material. Así, por un lado, enfatizan la noción de «obra» como programa y 
proceso que no se define necesariamente por su efectuación en una materia y, por el otro, experimentan materialmente con la visualidad de los signos y con tecnologías digitales dependientes no sólo de programas técnicos (software) sino también de aparatos técnicos (hardware) que a su vez dependen de la energía eléctrica, en cuanto materia sin masa pero materia al fin.

El propio Vigo en su texto sobre la poesía para y/o a realizar navega entre ambos aspectos y por ello habla tanto de ideas y programas como de un arte tecnológicamente realizable, esto es, materialmente realizable ${ }^{20}$. Lo que podría comprenderse como una especie de «conceptualismo tecnológico» que antes que desmaterializador o inmaterializador busca vincular una poesía de ideas-fuerza - no de obras - con materialidades heterogéneas a la poesía discursiva convencional. Todo lo cual cabía bajo el mote de novísima poesía.

\section{Nueva, novísima y no tanto novedosa: de Vigo a la poesía digital}

Ahora bien, ¿por qué novísima y no simplemente nueva? En muchas otras ocasiones, Vigo utilizó el adjetivo «nuevo» para caracterizar un tipo de arte que le resultaba de interés y quería difundir. En la tapa del número 20 de Diagonal Cero, por ejemplo, se lee "NÚMERO DEDICADO A LA NUEVA POESÍA PLATENSE». Como señala Fernando Davis (2009: 7), en marzo de 1968 Vigo publicó en la revista Los huevos de Plata — que dirigía Clemente Padín, otro artista central a la escena de la poesía experimental latinoamericana - un artículo titulado «Nueva vanguardia poética en Argentina». Pero ya en septiembre de ese año dictó una conferencia titulada "Panorama de la novísima poesía», en el Círculo de Periodistas de la Provincia de Buenos Aires en la que — según reseña aparecida en el diario El Día (El Día, 22 de septiembre de 1968) — prefirió reservar el término «vanguardia» para "todo el laboratorio experimental de comienzos de nuestro siglo» (El Día, 1968) y consideró que "novísima poesía» era el término que «reflejaba (...) más acertadamente las características revolucionarias» de las expresiones poéticas del momento. En los años sesenta, por otro lado, hablar de todo lo que era nuevo resultaba casi un must. Si se revisan las cajas del Archivo del Centro de Arte Experimental Vigo de esos años, se evidencia que adjetivos como "nuevo" y «actual» son recurrentes en los catálogos de distintas muestras de arte, así como en los recortes periodísticos que Vigo atesoraba. Y de hecho, esto se relaciona en gran medida tanto con la gran renovación de la vida cotidiana que caracterizó a esa década en Occidente - y de la que tanto se ha escrito (Jameson, 1984, King, 1985)— como con la modernización tecnológica que acompañó a esa renovación (Kozak, 2014b). Lo que terminó conduciendo a una asociación entre lo nuevo y la mera novedad como 
moda, como reemplazo constante de una cosa por otra para mantener en forma el consumo mercantil y la sociedad del espectáculo (Debord, 1967). A lo que Vigo, por supuesto, se oponía tajantemente. Novísima poesía fue así la fórmula que encontró para una poesía que está

en contra de una corriente de moda y sumamente explotada, el arte de consumo (...) Los intereses que se juegan detrás de éste nos obligan a tomar una posición vertical y de frente. La negación del hombre al masificarse por vía-espectáculo la aceptamos siempre que sume a ella su réplica, un arte intercomunicativo-lúdico-individual. (Vigo, 1979: 0'9, negritas en el original)

Y de ese modo, más que un consumidor, el antaño lector/receptor de poesía se convertía - a partir de un programador-facilitador de procesos y acciones- en un realizador del poema, por lo que la participación se daba en un nivel de «activación más profunda» (Vigo, 1970: 0’9).

Pero como queda dicho, la novísima poesía fue también la poesía de la «era tecnológica» (López Anaya, 1969, s.p.), que con sus «anexiones técnicas» (Vigo, 1970: 0'8) en alguna medida dialogaba con ese «masificarse por vía-espectáculo» (Vigo, 1970: 0’9), que era el espectáculo de los nuevos medios técnicos. Frente a eso, la tesitura del Movimiento Diagonal Cero parecía ser más bien la de una «inserción crítica» en esa era tecnológica. Por ejemplo Gancedo, en la presentación de su serie $I B M$, decía por un lado que «los equipos electrónicos mecanizados representan en sí mismo [sic] un poderoso poema» y, por otro lado, que «estos poemas [sus poemas IBM] no son un trabajo técnico, sino nuevos elementos técnicos usados en la ampliación del mundo poético" (Gancedo, 1966: 15). Esa inserción crítica es justamente algo que la poesía experimental digital contemporánea retoma en muchas ocasiones. Obras latinoamericanas paradigmáticas en tal sentido son por ejemplo El 27 / The 27th, del ya mencionado Eugenio Tisselli, una pieza de poesía conceptual algorítmica que interviene en el necrocapitalismo contemporáneo; Epithelia (1999) de la artista argentina de nuevos medios Mariela Yeregui o Postales (2000) de la también argentina artista visual Gabriela Golder. Estas dos últimas piezas mencionadas exhiben el «revés de la trama» de la cultura digital, al desacostumbrar la vinculación que tenemos con la navegación online que, en general, tiende a la amigabilidad y la eficiencia como modo de retener al internauta ${ }^{21}$.

La cultura digital contemporánea nos tiene acostumbrados a consumos bastante estandarizados que, aunque parecen ser siempre nuevos, tienden a adiestrar y hacer rutinarias nuestras percepciones y actuaciones en la vida cotidiana. Pero la poesía experimental digital trabaja muchas veces en la desautomatización de esas rutas estandarizadas. Una de las formas en que esto se da es el énfasis en el aspecto lúdico en la realización del poema. Algo que también resultaba fundamental en la concepción del arte experimental para Vigo. En cuanto la poesía digital es una poesía de dispositivo (Bootz, 2012), uno de sus sentidos es justamente su funcionamiento mismo que invita muchas veces a experimentar «jugando» con la máquina. Sin embargo, no todo se agota allí. Puesto que también la misma noción de interacción como juego puede reducirse a una sola idea, como sostenía José Luis Brea, de «apretar botoncitos» (Brea, 2002: 118), es decir, a una banalización acrítica de la interactividad. En las sociedades informatizadas contemporáneas apretamos botoncitos incansablemente. La poesía experimental digital en general 
pretende hacerlo contra la corriente abriendo posibilidades para experimentar nuevos modos de construcción sensible y cognitiva de nuestro estar en el mundo.

Otra forma de buscar la desautomatización de rutas estandarizadas es la del establecimiento de una relación no convencional entre programación y azar. Ya en su momento, según se desprende de su descripción, Gancedo tensionó los polos de programación y azar. Por una parte, pre-programó su poema perforando las tarjetas a partir del código estándar para ello. Cada letra del texto correspondía, de acuerdo al código, a dos perforaciones en una misma columna. Pero por otra parte, el poeta sostiene que las perforaciones fueron realizadas «usando combinaciones automáticas de acto "reflejo" traduciendo estados emotivos y ubicación visual» (Gancedo, 1966: 15). Esto significa que, si por un lado utilizó el código estandarizado que se usaba en la época en todas las empresas y organismos gubernamentales que implementaban el sistema de tarjetas perforadas para almacenar y decodificar información; al mismo tiempo desvió ese código a la manera de una escritura automática y dando prioridad al efecto visual que se obtenía en la tarjetas una vez perforadas. Además, siempre según su descripción, en relación con la Card Interpreter «se usaron paneles de controles con programación al azar» (Gancedo, 1966: 15). De allí que los textos de los tres poemas presenten algún grado de desajuste debido a ese desvío 22 .

De un lado, todo trabajo de literatura digital implica su programación informática, esto es, la predeterminación de un número importante de instrucciones que se seguirán para que la pieza pueda efectivizarse vía alguna interfaz, como por ejemplo, una pantalla. Lo que comporta una necesaria estandarización informática sin la cual las computadoras no podrían siquiera funcionar (Berti 2017). Nuestro mundo computarizado es así necesariamente estandarizado. Pero de otro lado, la literatura digital ha nacido claramente experimental y en muchas de sus realizaciones no renuncia a esa marca de nacimiento.

Los puentes que como aquí he desarrollado se pueden tender con el experimentalismo de las artes de los años sesenta del siglo XX —y de allí para atrás, con las vanguardias históricas - lo evidencian. Lo experimental en el arte, asociado como lo hacía Vigo a lo nuevo o incluso a lo novísimo, implica poner en marcha procesos de exploración de mundos que no se pueden predecir, esto es, ampliación de nuevas variedades de mundo abiertas a un acontecimiento. Lo que constituye aún hoy un desafío en nuestro mundo digital de artefactos digitales que se ofrecen como novedades de reemplazo constante. 


\section{Notas}

${ }^{1}$ Ciertamente podría argumentarse que la categoría misma de «obra», tal como ha sido propia de tradiciones teórico-críticas hermenéuticas para dar cuenta de "objetos artísticos» en tanto unidades cerradas sobre un significado y atribuibles a un autor originador y propietario (Barthes, 1971), no se adecua a las producciones de las que este artículo trata. Como se desprende de los aportes de Bürger (1974) para el estudio de las vanguardias históricas y Barthes (1971) para la conceptualización de una mirada sobre la literatura concentrada en el "texto» más que en la obra, la noción de obra entiende al «objeto artístico» como orgánico — siendo siempre sus partes funcionales a una totalidad — y en vinculación con un autor, un estilo y un significado. Así, después de Barthes, la crítica literaria que pretendió desasirse de dicha noción de obra, prefirió entonces utilizar la palabra "texto" para referirse a sus objetos de análisis —y si se me permite una mención autobiográfica, he optado siempre que me fue posible por dicho término y concepto- Con todo, para el tipo de producciones que ocupan a este artículo el término «texto» no resulta tampoco del todo pertinente, en cuanto suele quedar vinculado sobre todo al lenguaje verbal. Así, utilizo alternativas como "producciones", «prácticas» $\mathrm{o}$ «piezas» siempre que resulta posible sin oscurecer el sentido de lo que se pretende enunciar. Si en algunos casos, utilizo aún la palabra «obra» lo hago para no redundar en alternativas o perífrasis.

${ }^{2} \mathrm{El}$ presente artículo no tiene como objetivo desarrollar un abordaje integral de la poesía digital sino analizar las maneras en que la poética de Edgardo Antonio Vigo resuena en parte importante de las producciones de poesía digital contemporáneas. Como se anticipa en el resumen, se trata de analizar vinculaciones entre la poética de Vigo y la poesía digital y no de analizar esta poesía digital en particular, lo que conduciría a otro artículo. Enmarco la poesía digital en la literatura digital, objeto del que he dado cuenta en distintas publicaciones anteriores (Kozak, 2015, 2017a y 2017b, entre otras). Destaco en forma sucinta que entiendo por literatura digital un tipo de producción artística, por lo general multimedia y que por ello constituye una zona de las artes digitales. Su especificidad débil al interior de la noción más general de artes digitales radica en evidenciar un alto grado de implicación —aunque no exclusiva - del lenguaje verbal con función poética, inscribiéndose marginalmente en la institución literaria a partir de un diálogo con la historia literaria en general, y con la literatura tecno-experimental en particular. A diferencia de la literatura asociada al medio libro, es literatura generada en/por/ desde/hacia dispositivos electrónicos, actualmente digitales, es decir, por fuera de medios electrónicos analógicos (la radio, la televisión, el video analógico grabado en cintas magnéticas, por ejemplo). Literatura programada en código binario a través de la creación y uso de diversos software y experimentada en vinculación con interfaces digitales. No es literatura digitalizada, como traslado de textos desde el medio impreso a la pantalla de una computadora, sino nacida digital y en cuyos procedimientos es intrínseca la creación o utilización del código digital informático.

${ }^{3}$ Si seguimos a Adorno (1970: 40), lo experimental en el arte se da toda vez 
que lo nuevo es vinculante. De manera muy característica, lo experimental pasó según el autor desde una primera etapa histórica en la que implicó "que una voluntad consciente de sí misma ensayaba formas de proceder desconocidas o no sancionadas" (Adorno 1970: 39) hasta una segunda etapa concentrada en lo imprevisible, en la que «el sujeto artístico practica métodos cuyo resultado real no puede prever.» (Adorno 1970: 40). ${ }^{4}$ Neide Dias, casada con Álvaro de Sá, aparece muchas veces referenciada con el apellido de casada como Neide de Sá. Con todo, opto aquí por consignar también su apellido de soltera.

${ }^{5}$ Respeto aquí la particular paginación habitual de las publicaciones de Vigo.

${ }^{6}$ Neide Dias, casada con Álvaro de Sá, aparece muchas veces referenciada con el apellido de casada como Neide de Sá. Con todo, opto aquí por consignar también su apellido de soltera.

${ }^{7}$ Estas producciones pueden consultarse, respectivamente, en: http:// motorhueso.net/ y https://www.miltonlaufer.com.ar/.

${ }^{8}$ Para un análisis de esta pieza, ver Kozak (2017a).

${ }^{9}$ Espen Aarseth es autor de uno de los primeros libros que abordan de manera comprensiva la literatura digital. El autor lo hace acuńando la categoría de «literatura ergódica» desde entonces muy referenciada en el campo específico. Se trata de literatura cuya característica principal sería que modifica la actividad de lectura, haciendo que quien interactúa con ella deba realizar un trabajo (ergon) por el camino (bodos) del texto. ${ }^{10} \mathrm{Si}$ bien en números anteriores de la revista había ya algunos acercamientos al trabajo poético visual, como en el poema «Mi ciudad» de Vigo, publicado en el número xx y cuyos versos estaban dispuestos perpendicularmente en relación con la base de la página, lo que remedaba el perfil de un paisaje urbano, es el número 20 el que efectúa el viraje decisivo que tomará la revista hacia la poesía visual.

${ }^{11}$ La descripción del proceso de producción de estos poemas IBM, no del todo clara por cierto, aparece en el número 20 de Diagonal Cero al comienzo de la sección donde se reproducen luego los poemas. He analizado este primer poema digital argentino en publicaciones previas. ${ }^{12}$ En ocasión de la publicación en la Argentina de su libro Happenings, Jean-Jacques Lebel realizó un happening en el Instituto Di Tella el 28 de marzo de 1967. Los distintos volantes arrojados por Vigo en esa oportunidad, cada uno con un poema de integrantes del Movimiento Diagonal Cero (es ese caso: Jorge de Luxan Gutiérrez, Omar Gancedo, Luis Pazos y le propio Vigo) están archivados en la caja n 6 del Archivo del Centro de Arte Experimental Vigo, en la ciudad de La Plata, también disponibles en documentos escaneados digitalmente en su sitio web (http://caev.com.ar/upload/files/CAJA\%206\%20-\%201966-67.pdf).

${ }^{13} \mathrm{El}$ poema de Hidalgo fue publicado en Química del espiritu (1923).

${ }^{14} \mathrm{Se}$ puede acceder a las obras mencionadas en: http://belengache.net/, https://www.miltonlaufer.com.ar/, http://www2.uol.com.br/augustodecampos/poemas.htm, http://www.ivan-marino.net/. He analizado producciones de Läufer en Kozak (2017b) y de Marino en (Kozak 2014). 
${ }^{15}$ Se puede acceder a esta obra en diferentes versiones que emulan la programación original en el sitio web del poeta/programador Jim Andrews (http://www.vispo.com/). También en ese sitio se puede acceder a la obra de Ana María Uribe, una de las primeras realizadoras argentinas de poesía digital.

${ }^{16}$ En este caso, citamos la carta que está reproducida en el libro editado por Anna Higgins y Douglas Kahn, Mainframe Experimentalism. Early Computing and the Foundations of the Digital Arts (2012). El libro da cuenta del experimentalismo tecnológico en la época de las primeras (grandes) computadoras como antecedente del arte digital más contemporáneo. ${ }^{17}$ Como comenta en la carta ya citada (Williams 1973b: 275), la idea de retomar el modelo de poemas combinatorios que había ensayado en los años cincuenta surgió en 1966 cuando le fue ofrecido por primera vez "hacer algo» con una computadora. Una vez realizado el experimento fue según dice «olvidado» hasta que su esposa le mostró algunos años más tarde el funcionamiento de una máquina de fotocomposición de textos, la Diatype, que permitía modificar el tamańo de las fuentes. Como se desprende de la carta, y precisa Funkhouser (2017: 3), el aspecto visual fue incorporado cuando Williams comenzó a utilizar la Dyatype para aumentar el tamańo de una palabra cada vez que se repetía por la puesta en marcha de las reglas que seguía el programa.

${ }^{18}$ No es el objeto de este artículo presentar y desarrollar en detalle los distintos formatos o "géneros" que ha adoptado hasta el momento la literatura digital. Como he tratado en trabajos previos (Kozak 2017 a y b), para poder dar cuenta de tipos de literatura digital más allá de la clasificación por sí misma sino más bien, al decir de Bajtin (1936) y Bajtin y Medvedev (1928), como maneras de «finalización» de la realidad, esto es, de algún modo, "máquinas de percepción y sentido», sería preciso construir un modelo de variables cruzadas que tenga en cuenta también, además del carácter genérico vinculado a modos del discurso (narrativo, lírico, o incluso dramático), otras variables en función de: modalidades constructivas como conectividad (on/offline), automatismo (generatividad algorítmica/no generatividad), interactividad (sí/no); direccionalidad (linealidad/hipertexualidad e hipermedialidad); autoría (individual, colaborativa en producción, colaborativa en recepción); lenguajes (verbal, visual, sonoro, imagen-movimiento) y soportes, esto es, tipo de interfaz (computadora, teléfono móvil, tablet, pantalla en espacio público).

${ }^{19}$ En la caja ${ }^{\circ} 6$ del Archivo del Centro Experimental Vigo, correspondiente a los años 1966 y 1967 no aparecen documentos de los cuales inferir que Vigo o Gancedo conocieran el poema "IBM» de Williams en 1966. Por otra parte, si bien en la biblioteca de Vigo se encuentra la edición original de 1967 del libro An Anthology of Concrete Poetry editado por Williams, el poema titulado "IBM» fue recién publicado en libro en 1973.

${ }^{20}$ En concordancia, el texto introductorio de Jorge López Anaya para el catálogo de Novísima Poesía/69 se titula «Situación de la poesía en la era tecnológica». 
${ }^{21}$ He analizado El 27/ The 27th en Kozak (2017a y c) y Postales en Kozak (2017a). Un desarrollo amplio sobre la producción de Mariela Yeregui y Gabriela Golder en relación con su «impulso literario» puede consultarse en Kozak (2018), en prensa.

${ }^{22}$ En otras publicaciones (Kozak, 2015 y 2016) he analizado con más detalle esta serie de poemas IBM de Gancedo. Un análisis tal excedería los objetivos del presente artículo así como los límites de extensión del dossier.

\section{Referencias bibliográficas}

Aarseth, E. (1997). Cybertext. Perspectives on Ergodic Literature. Baltimore: The John Hopkins University Press.

Adorno, Th. W. (1970) Teoría estética. [Traducción al espańol de: Fernando Riaza] (1983). Barcelona: Orbis.

Bajtin, M. (1936). El problema de los géneros discursivos. En Estética de la creación verbal (1982). México: Siglo XXI

Bajtin, M. y Medvedev, P. (1928). Chapter Seven: The Elements of Artistic Construction. En: The Formal Method in Literary Scholarship (Pp. 129-141). Baltimore and London: The John Hopkins University Press. Barisone, O. (2012). Vigo y la Expo Internacional Novisima Poesía/69 (CAV-ITDT, 1969) como materialización del intercambio. Posibilidades del concretismo. En VIII Congreso Internacional de Teoría y Crítica Literaria Orbis Tertius. Recuperado online www.memoria.fahce.unlp. edu.ar/trab_eventos/ev.1569/ev.1569.pdf

Barthes, R. (1971). De la obra al texto [Traducción al español de: C. Fernández Medrano]. En El susurro del lenguaje. Más allá de la palabra $y$ de la escritura. (1994). Barcelona: Paidós.

Beiguelman, G. (2010). The Reader, the Player, and the Executable Poetics. Towards a Literature Beyond de Book. En Schäfer, Jórgen And Gendolla (eds.) Beyond the Screen: Transformations of Literary Structures, Interfaces and Generes (pp. 403-425). Bielefeld: Transcript Verlag. Berti, A. (2017). La referenciabilidad discreta de las Palabras esquivas: procedimientos de la Poesía web argentina. Perífrasis, (n 15), 10-28. Recuperado online de https://revistaperifrasis.uniandes.edu.co/images/ versiondigital/vol8n15/vol8n15.pdf

Brea, J.L. (2002) La era postmedia. Acción comunicativa, prácticas (post) artísticas y dispositivos neomediales. Salamanca: Editorial CASA Centro de Arte de Salamanca. Recuperado online http://medialab-prado.es/ mmedia/10509/view

Boотz, Рн. (2012). La poesía digital programada: una poesía del dispositivo. En Kozak, C. (Comp.), Poéticas tecnológicas, transdisciplina y sociedad: Actas del Seminario Internacional Ludión-Paragraphe: 31-40. Recuperado online de http://www.ludion.org /articulos.php?articulo_id=54. Bürger, P. (1974). Teoría de la vanguardia. (1987) [Traducción al español de: Jorge García]. Madrid: Península.

Cirne, M. (1970). De la poesía concreta a la poesía proceso. En Vigo, 
E.A. Poesía para y/o a realizar (pp. 1'1-1'3). La Plata: Ediciones Diagonal Cero.

Davis, F. (2006). Poéticas oblicuas. Diagonal Cero y la poesía "para y/o a realizar» en Edgardo Antonio Vigo (1962-1970). En AA.VV. 2das. Jornadas de Investigación en Disciplinas Artísticas y Proyectuales La Plata. La Plata: Facultad de Bellas Artes-UNLP. Recuperado online de http:// sedici.unlp.edu.ar/bitstream/handle/10915/39213/Documento_completo.pdf?sequence $=1$

(2009). Prácticas revulsivas. Edgardo Antonio Vigo en los márgenes del conceptualismo. En Freire, C. y Longoni, A. (Eds.). Conceitualismos do Sul/ Conceptualismos del Sur, São Paulo, Annablume. Recuperado online de http://servicios2.abc.gov.ar/lainstitucion/sistemaeducativo/educacionartistica/34seminarios/htmls/descargas/bibliografia/ problematicas-arte/4-Davis.pdf

(2016) Poéticas oblicuas. Grabado, cuerpos y poesía en Diagonal Cero. América lee. El portal de publicaciones latinoamericanas del siglo XX. Recuperado online de http://americalee.cedinci.org/portfolio-items/ diagonal-cero/

Debord, G. (1967) La sociedad del espectáculo y otros textos situacionistas. (1974) Buenos Aires: De la Flor.

Dias De Sa, N. (s/f) Poesia experimental. Entrevista de Regina Célia Pinto. Musseu do essencial e do além disso. Recuperado online de http:// arteonline.arq.br/museu/interviews/neide.htm

El Día. (1968) Sobre la novísima poesía disertó el Prof. Edgardo Vigo. La Plata, 22 de septiembre. En Caja 7-1968, Archivo del Centro de Arte Experimental Vigo. Recuperado online de https://www.dropbox.com/s/ q38wm8rkta257ev/CAJA\%207-1968\%20WEB.pdf Expo/Internacional de Novísima Poesía/69. (1969). Catálogo. Centro de Artes Visuales del Instituto Torcuato Di Tella.

Funkhouser, CH. (2017). IBM Poetry: Exploring Restriction in Computer Poems. Humanities (6.1). doi:10.3390/h6010007

(2007) Prehistoric Digital Poetry. An Archeology of Forms, 1959-1995. Tuscaloosa: The University of Alabama Press.

Glazier, L.P. (2002) Digital Poetics. The Making of E-Poetries. Tuscaloosa: The University of Alabama Press.

Gradín, Ch. (2014). Edgardo Antonio Vigo, o el arte digital desenchufado. En Kozak, C. (Comp.) Poéticas/políticas tecnológicas en Argentina (1910-2010) (197-210). Paraná: La Hendija.

Hayles, N.K. (2006). The Time of Digital Poetry: From Object to Event. En: Morris, A. and Swiss, Th. (Eds.). New Media Poetics. Contexts, Technotexts and Theories (181-209). Cambridge, Massachusetts: The MIT Press. (2008). Literatura Eletrônica. Novos horizontes para o literário. [Traducción al portugués de: Luciana Lhullier y Ricardo Moura Buchweitz] (2009). São Paulo, Global Editora/Universidade de Passo Fundo. Jameson, F. (1984). Periodizing the 60s. En The 60s Without Apology. Minneapolis: University of Minnesota Press.

KING, J. (1985). El Di Tella y el desarrollo cultural argentino en la década del sesenta. Buenos Aires: Ediciones de Arte Gaglione. 
KozaK, C. (2014a). Del modo de existencia de los objetos tecno-literarios. Pequeńo diccionario personal ilustrado de literatura digital. En: Panesi, J. y otros. IX Argentino de Literatura (51-62), Santa Fe, UNL. Recuperado online de http://www.fhuc.unl.edu.ar/centros/cedintel/ argentino.pdf

(2014b). Más allá de la primera plana. Modernización e imaginario tecnológico en revistas culturales argentinas a mediados del siglo XX. En Kozak, C. (Comp.) Poéticas/políticas tecnológicas en Argentina (1910-2010) (65-92). Paraná: La Hendija.

(2015). Mallarmé e IBM. Los inicios de la poesía digital en Brasil y Argentina. Ipotesi, (19:1) 191-200. Juiz de Fora: UFJF. Recuperado online de http://www.uff.br/revistaipotesi/files/2016/01/15Mallarm\%C3\%A9-e-IBM-19-n1.pdf

(2016). Por una literatura fuera de sí. IBM de Omar Gancedo. En Torres, A. y Pérez Balbi, M. (Comps.). Visualidady dispositivo. Los cruces entre el arte y la técnica desde una perspectiva cultural (35-47). Los Polvorines: Ediciones UNGS.

(2017a). Literatura expandida en el dominio digital. En El taco en la brea, (6) 220-245. Recuperado online de http://bibliotecavirtual. unl.edu.ar/ojs/index.php/ElTacoenlaBrea/article/view/6973/10168

(2017b). Esos raros poemas nuevos. Teoría y crítica de la poesía digital latinoamericana. En El jardín de los poetas. Revista de teoría y critica de poesía latinoamericana (4). Recuperado online de http:// cajaderesonancia.com/jardin-detalle.php?id=240

(2017c). Latin American Electronic Literature: When, Where and Why. En Mencía, M. (ed.). \#Women TechLit (PP. 55-72). Morgantown, WV: West Virginia University Press.

(2018). Words, Memory and Space in Intermedial Works by Gabriela Golder and Mariela Yeregui. En Lavery, J. y Bowskill, S. (eds.), The Multimedia Works of Contemporary Spanish American Women Writers and Artists - Text, Image, and the Sensory. Albany, NY: SUNY Press (Gender in the Global South Series), en prensa.

López Anaya, J. (1969). Situación de la poesía en la era tecnológica. En Novísima Poesía/69. Catálogo. La Plata: Museo Provincial de Bellas Artes. Novísima Poesía/69. (1969). Catálogo. La Plata: Museo Provincial de Bellas Artes.

Pérez Balbi, M. (2007) «Movimiento Diagonal Cero: poesía experimental desde La Plata (1966-1969)». En Escáner cultural. Revista de arte contemporáneo y nuevas tendencias 9(96) [en línea]. Consultado el 2 de agosto de 2013 en http://revista.escaner.cl/node/277

(2010). Poesía experimental desde La Plata. Crónica del Movimiento Diagonal Cero (1966-1969). Boletín de Arte (12), 75-92 Recuperado online de http://sedici.unlp.edu.ar/handle/10915/18593 Perloff, M. (2006). Screening the Page/Paging the Screen: Digital Poetics and the Differential Text. En: Morris, A. y Swiss, Th. (Eds.). New Media Poetics. Contexts, Technotexts and Theories (pp. 143-162). Cambridge, Massachusetts: The MIT Press. 
Vigo, E.A. (1970). De la poesíalproceso a la poesía para y/o a realizar. La Plata: Diagonal Cero Editora.

Williams, E. (1967). An Anthology of Concrete Poetry. New York: Something Else Press.

(1973a). A Valentine for Noël: Four Variations on a Scheme. Barton: Something Else Press.

(1973b). A letter to Ann Noël. En Higgins, A. B y Kahn, D. (Eds.). Mainframe Experimentalism. Early Computing and the Foundations of the Digital Arts. (2012) Berkeley and Los Angeles: University of California Press.

\section{Kozak, Claudia}

«¿Nueva, novísima o novedosa? De la novísima poesía según Edgardo Antonio Vigo a la poesía experimental digital». El hilo de la fábula. Revista anual del Centro de Estudios Comparados (18), 185-202.

Fecha de recepción: $18 \cdot 02 \cdot 18$

Fecha de aceptación: $27 \cdot 02 \cdot 18$ 